\title{
Possibilities and Limitations of Mercury and Mercury-based Electrodes in Practical Electroanalysis of Biologically Active Organic Compounds
}

\author{
Jiri Barek \\ Charles University in Prague, Faculty of Science, University Research Center UNCE \\ "Supramolecular Chemistry", Department of Analytical Chemistry, UNESCO Laboratory of \\ Environmental Electrochemistry, Albertov 6, CZ-128 43 Prague 2, Czech Republic
}

Received 20 December 2013; accepted 31 December 2013

\begin{abstract}
Personal opinion of the author on the use of mercury and amalgam electrodes for determination of trace amounts of biologically active organic compounds is expressed. This view is supported by references to numerous reviews and original papers from UNESCO Laboratory of environmental electrochemistry supporting the claim that both mercury and amalgam electrodes can play useful role in modern practically oriented analytical laboratories.
\end{abstract}

Keywords: mercury electrodes, amalgam electrodes, polarography, voltammetry, amperometry, biologically active organic compounds.

\section{Introduction}

The recent trends in the field of electroanalytical chemistry are focused on the development of "smart" electrodes modified by various chemical, biological or nanoparticles-based systems. These electrodes usually work reasonably well in the hands of experienced electroanalytical chemist but their practical applications are limited by their low robustness and high requirements on handling analysts. It is the aim of this "opinion article" to stress that in many cases practice prefers simple, easy operated "foolproof" electrodes with simple pretreatment and high reliability. And to show that mercury and mercury based electrodes even more

\footnotetext{
* Corresponding author. E-mail address: jiri.barek@natur.cuni.cz
} 
than ninety years after their introduction are probably the best sensors for the determination or trace amounts of electrochemically reducible organic compounds.

\section{Mercury electrodes}

Since 1922, when Professor Jaroslav Heyrovský introduced a dropping mercury electrode (DME), polarography showed remarkable ability to adjust to ever increasing demands on the sensitivity and selectivity and, up to now, mercury electrodes are among the best sensors for electroanalytical measurements [1-4]. Thanks to developments in instrumentation, potential programs and the treatment of current response, limits of determination (LOD) gradually decreased from $10^{-5}$ mol $\mathrm{L}^{-1}$ for classical DC polarography (DCP), through $10^{-6} \mathrm{~mol} \mathrm{~L}^{-1}$ for DC tast polarography (DCTP) and $10^{-7} \mathrm{~mol} \mathrm{~L}^{-1}$ for AC polarography (ACP), normal pulse polarography (NPP), and differential pulse polarography (DPP) to $10^{-8} \mathrm{~mol}$ $\mathrm{L}^{-1}$ for square-wave polarography (SWP). Adsorptive striping voltammetry (AdSV) [5] enabled further decrease of LOD down to $10^{-9}-10^{-11} \mathrm{~mol} \mathrm{~L}^{-1}$ thanks to the adsorptive accumulation of analytes on the surface of hanging mercury drop electrode (HMDE). Comprehensive list of useful practical applications can be found in above quoted reviews. However, somewhat unreasonable fears of mercury toxicity complicate the use of metallic mercury in practical analytical laboratories. These fears are not too rational because mercury is practically innocuous at room temperature (toxic organomercury compounds are not formed during electrochemical measurements). Moreover, the amount of mercury used for one determination can be dramatically decreased by the use of static mercury drop electrodes (SMDE) and HMDE.

It is necessary to admit that routine applications of mercury electrodes are not too frequent nowadays because of fast developments of modern spectrometric and separation techniques, above mentioned concerns about mercury toxicity, the lack of properly validated methods, and a lower activity of producers of electroanalytical instrumentation in comparison with producers of spectrometric and separation instruments. The dwindling number of university teachers involved in electroanalytical research plays a negative role, as well as shrinking position of electroanalytical methods in the curriculum of most universities. Nevertheless, both polarography and voltammetry at mercury electrodes can still play useful role in analytical laboratories for the determination of a given compound in a given matrix because of broad linear dynamic range and low limits of determination, low running and investment costs, reasonable selectivity especially in combination with preliminary separation and sample clean-up. Moreover, electroanalytical methods present an independent alternative to prevailing spectrometric or separation methods which is important in those cases where the analytical results should be "beyond reasonable doubts" (speaking in law terms) which, according to many regulations, requires the application of several independent analytical methods. Thousands of reliable methods based on the application of mercury electrodes are available in scientific journals, monographs, tables, and databases and even today quite a number of new 
methods using mercury electrodes are published every year confirming their practical applicability. Economic reasons make those methods especially useful for screening purposes and for large scale monitoring of electrochemically reducible organic compounds. For organic compounds containing nitro, nitroso, azo or heterocyclic moiety (e.g. many priority environmental pollutants [6], pesticides [7], drugs and their metabolites, dyes [8], biomarkers of exposition and/or illness, etc.) mercury electrodes are up to now the best available sensors which can successfully compete with many other analytical processes in terms of price, speed, sensitivity and simplicity. These advantages in many cases far outweigh a disadvantage connected with exaggerated problems of mercury toxicity. Solid electrodes (noble metals, various types of carbon, etc.) have much narrower cathodic potential window and thus cannot compete with mercury in this region. Carbon paste electrodes $[9,10]$ offer the advantage of easy surface renewal, however, their application in cathodic region is also limited. The most suitable carbonaceous electrode material for cathodic region is thus probably boron doped diamond [11,12]. From other non-traditional electrode materials only mercury amalgam (see further) and bismuth film [13] seem to be a promising alternative to mercury electrodes for direct cathodic electrochemical detection of organic compounds.

For large scale monitoring or for screening purposes of many organic analytes mercury electrodes can still successfully compete with other electrochemical, spectrometric or separation techniques. Moreover, they are indispensable as a tool for investigation of mechanism of electrochemical reduction of organic compounds, which is important for basic research, structure-activity relationship investigation, study of supramolecular interactions, etc. Moreover, thus obtained knowledge can be a useful clue for the study of biological redox processes and the transformation of investigated substances in ecosystem and for development of new analytical methods for pharmaceutical analysis (both the determination of selected drugs in pharmaceutical preparations and their traces or metabolites in body fluids, such as whole blood, plasma, urine), for food analysis (determination of residues of selected pesticides or growth stimulators), forensic analysis (determination of traces of gun powder or explosives), toxicology (determination of selected toxic substances in the general or working environment and their metabolites in body fluids, biological monitoring of the exposition to toxic substances, etc.), and environmental analysis (determination of selected anthropogenic pollutants, pesticides, genotoxic substances, chemical carcinogens, ecotoxic dyes, etc. in rain, surface, river, sea and drinking water and in other constituents of the environment). Methods based on mercury electrodes are undeservedly perceived as less selective, but they offer certain degree of selectivity because not all constituents of most samples are electrochemically active in cathodic region. This can be demonstrated by simple determination of nitrated polycyclic aromatic hydrocarbons in the presence of parent polycyclic aromatic hydrocarbons, which do not interfere, by the determination of drugs in tablets, injection liquids, or body fluids, etc. These determinations can be carried out in certain cases in the presence of colloid particles, solids, colored and surface-active substances. 


\section{Amalgam electrodes}

Although mercury should not be phased out and DME, SMDE and HMDE are definitely not obsolete, it is necessary to admit two obvious drawbacks of mercury electrodes, namely limited potential window in anodic region and low mechanical stability which complicate their application for measurements in flowing systems and for field measurements. Both mechanical stability ant toxicity problems were successfully addressed by the development of silver solid amalgam electrodes [14-24]. These electrodes are non-toxic (mercury amalgam is used in dentistry for centuries without any obvious detrimental effects), mercury vapor pressure above them is negligible [17], they are mechanically stable and thus compatible with measurement in combination with flowing systems (HPLC-ED or FIA-ED) [e.g. 23]) and they have potential window comparable with HMDE. The fact that their surface is not as easily renewable as in the case of DME, SMDE, or HMDE can be compensated by easy electrochemical regeneration of their surface (eliminating most problems connected with their passivation) by a series of suitably selected cleaning pulses. Another possibility is to use amalgam paste electrodes the surface of which can be simply renewed by simple wiping off the surface layer of the amalgam paste based either on paste amalgam only [24] or on solid amalgam powder mixed with a suitable organic pasting liquid [22]. Probable the most reliable and most reproducible is so called mercury meniscus modified silver solid amalgam electrode (m-AgSAE) or so called polished silver solid amalgam electrode ( $\mathrm{p}$ AgSAE), single crystal silver solid amalgam electrode [21] and mercury film electrode prepared on AgSAE substrate [19] being used less frequently. Optimum conditions for determination of micromolar and submicromolar concentrations of electrochemically reducible organic compounds can be found in quoted references. Moreover, in some cases AdSV can be used to further decrease LOD. However, it is fair to admit that LOD at amalgam electrodes are in most case at least one half of concentration order higher than those obtained at DME or HMDE.

\section{Conclusion}

Hundreds or even thousands of practical applications of both mercury and amalgam electrodes for determination of trace amounts of biologically active organic compounds in various biological and environmental matrices can be found in scientific literature. The practical analytical laboratories working in this field should be aware of this fact and should try to increase the frequency of practical applications based on those electrodes especially because of economic and productivity reasons.

\section{Acknowledgement}

Financial support from the Grant Agency of the Czech Republic (Project P206/12/G151) is gratefully acknowledged. 


\section{References}

1. Vyskočil V, Barek J. Crit Rev Anal Chem. 2009;39:173-188.

2. Barek J, Fogg AG, Muck A, et al. Crit Rev Anal Chem. 2001;31:291-309.

3. Zuman P. Crit Rev Anal Chem. 2001;31:281-289.

4. Kalvoda R. Chem Anal (Warszaw). 2007;52:869-873.

5. Barek J, Peckova K, Vyskocil V. Curr Anal Chem. 2008;4:242-249.

6. Vyskočil V, Barek J. Curr Org Chem. 2011;15:3059-3076.

7. Fischer J, H. Dejmková H, Barek J. Curr Org Chem. 2011;15:2923-2935.

8. Zima J, Barek J, Moreira JC, et al. Crit Rev Anal Chem. 1999;29:125-129.

9. Zima J, Švancara I, Barek J, et al. Crit Rev Anal Chem. 2009;39:204-227.

10. Švancara I, Zima J. Curr Org Chem. 2001;15:3043-3058.

11. Peckova K, Musilova J, Barek J. Crit Rev Anal Chem. 2009;39:148-172.

12. Peckova K, Barek J. Curr Org Chem. 2011;15:3014-3028.

13. Švancara I, Prior C, Hočevar SB, et al. Electroanalysis. 2010;22:1405-1420.

14. Barek J, Fischer J, Navratil T, et al. Sensors. 2006;6:445-452.

15. Yosypchuk B, Navratil T, Barek J, et al. In: Lefebvre MH, Roux MM, editors. Progress on Drinking Water Research. New York: Nova Science Publishers; 2008. P. 143-170.

16. Yosypchuk B, Barek J. Crit Rev Anal Chem. 2009;39:189-203.

17. Jiranek I, Cerveny V, Barek J, et al. Anal Lett. 2010;43:1387-1399.

18. Vyskocil V, Danhel A, Fischer J. et al. In: Vytřas K, Kalcher K, Švancara I. editors. Pardubice: University of Pardubice; 2010. P. 13-31. (vol 5).

19. Yosypchuk B, Fojta M, Barek J. Electroanalysis. 2010;22:1967-1973.

20. Danhel A, Barek J. Curr Org Chem. 2011;15:2957-2969.

21. Danhel A, Mansfeldova V, Janda P, et al. Analyst. 2011;136:3656-3662.

22. Danhel A, Yosypchuk B, Vyskocil V, et al. J Electroanal Chem. 2011;656:218-222.

23. Tvrdikova J, Danhel A, Barek J, et al. Electrochim Acta. 2012;73:23-30.

24. Niaz A, Fischer J, Barek J, et al. Electroanalysis. 2009;21:1786-1791. 